\title{
Mechanical Model of Steel-concrete Composite Joint under Sagging Bending Moment
}

\author{
Zdzisław Pisarek \\ Rzeszów University of Technology \\ Faculty of Civil and Environmental Engineering \\ e-mail: pisarzdz@prz.edu.pl
}

\begin{abstract}
In buildings with steel-concrete composite floors, joints are designed to transmit mainly hogging bending moment. In case of the large horizontal loads due to wind, earthquake or accidental events, sagging bending moments in a joint can also occur. Additionally, large deformations of the structure cause tying and prying effects. In the paper, a mechanical model based on "component method" for evaluation of characteristics of the composite joint is presented. The influence of tying and prying actions on distribution of the internal forces in a joint is also analyzed. The procedure for calculation of the characteristics of the composite joint with bolted endplate connection is elaborated too.
\end{abstract}

Key words: steel-concrete composite structures, joints, accidental actions, mechanical model, component method

\section{Introduction}

In recent years, the most popular are buildings with steel-concrete composite floors. In these buildings, joints are designed to transverse mainly hogging bending moment, where shear and compression forces are transferred by pure steel beam to column connection and tension force is transferred by reinforced steel bars (Fig. 1a). In case of the large horizontal loads due to wind, earthquake or accidental events, sagging bending moments in a joint can also occur. Then the concrete slab is in compression and steel connection in tension zone (Fig. 1b).

We can here distinguished two cases. When the structures are loaded by side-load of the wind, or earthquake about not large amplitude, then the static scheme of the structures does not change. The moment direction is changed only. In accidental cases, when column is damaged by detonated explosives in close range, impact of vehicle or fire, the static scheme of the structure is changed. Usually this is connected also with large structure deformations. 
a)

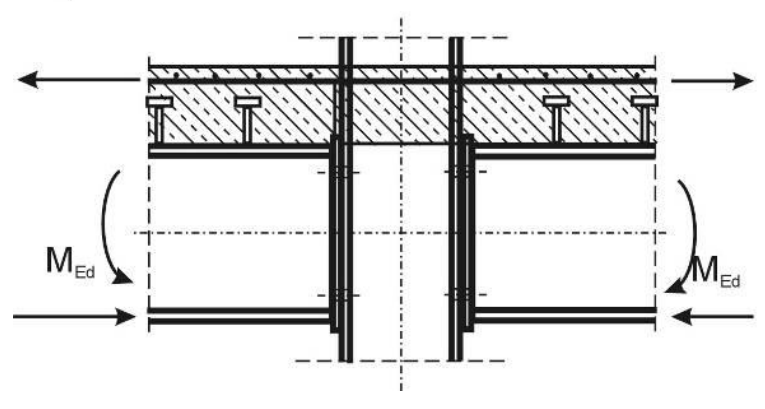

Figure 1: Beam column end-plate joint under b)

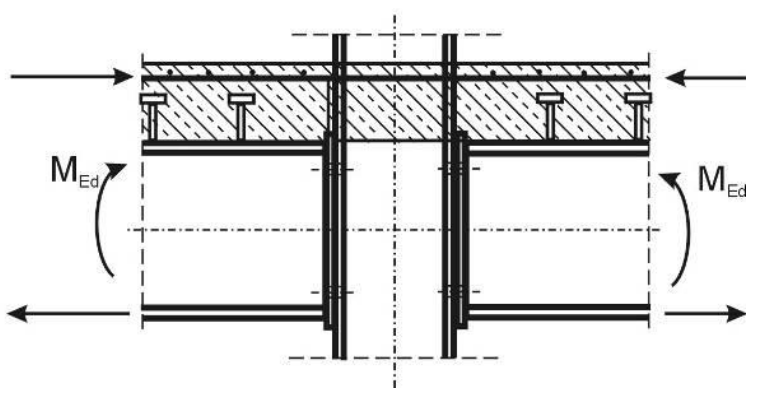

a - hogging bending moment, $\mathrm{b}$ - sagging bending moment.

In the design, loads from the removed column are transferred to the rest of the structure trough the beam action or catenary action in 2D structural systems. In 3D frames the loads are transferred trough truss systems or slab arching. 3D work of the structure is depended on their configuration. In $2 \mathrm{D}$ work, mechanism of load transfer is depended on characteristics of the joints.

When the joints are relatively stiff, loads are transferred by beam action. Beams adjacent to the damaged column become continuous and can be treat as a beam with double span (Fig. 2a). In case when the joints are weak or large deformations of the structure occur, the beams are in catenary action (Fig. 2b).

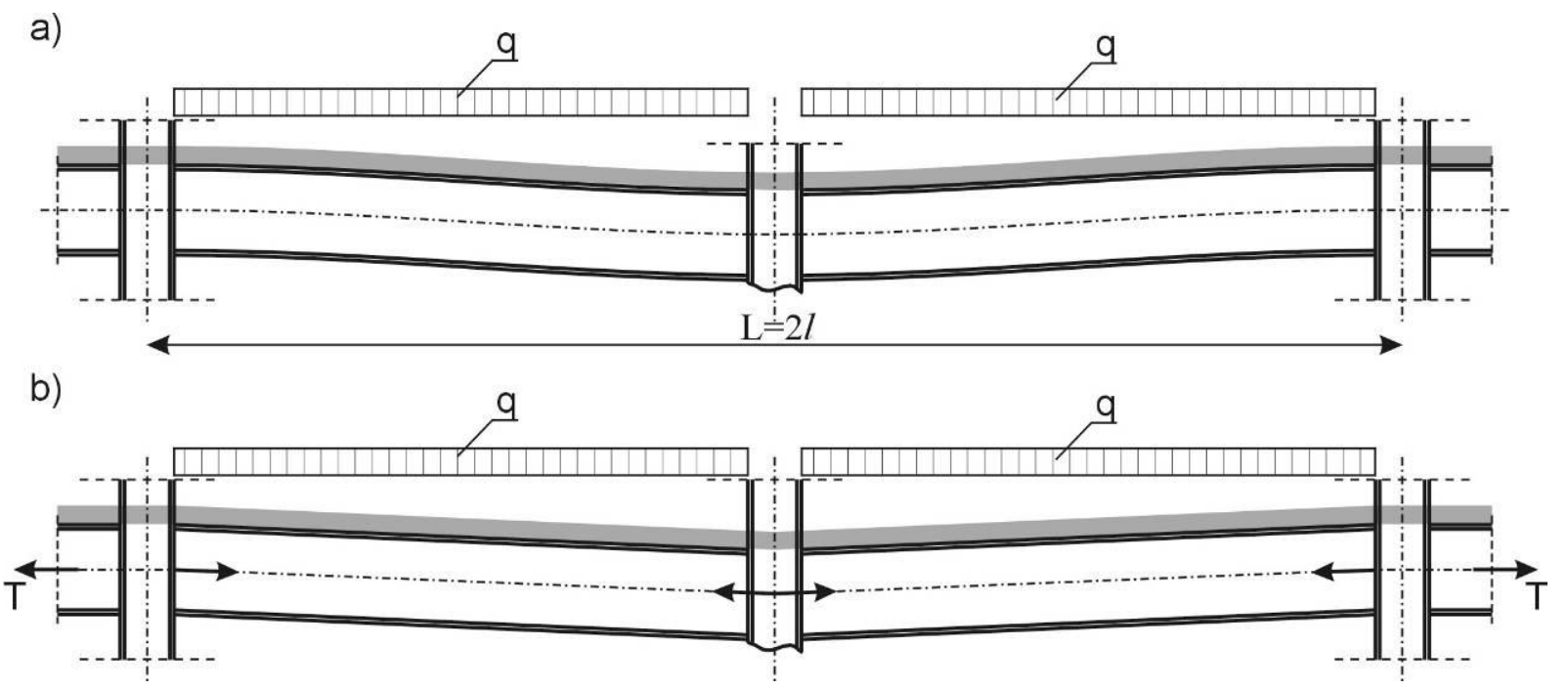

Figure 2: Mechanism of the load transferring:

a) double span beam action,

b) catenary action.

In Eurocode 4 [1], are presented the design rules for the evaluation of the resistance and rotational stiffness of the structural steel-concrete composite joints. These rules concern the situation where the joints are subjected to hogging moment only. 


\section{Resistance of the composite joint}

In beam to column joint are distinguished three zones - tension, compression and shear zone. In joints subjected to the sagging bending moment, tension zone can be treated as a pure steel connection. This connection can be analysed according formulae given in [2]. Web panel of the column also can be checked according to [2]. In case when the web panel of the column is encased, their resistance should be increased according [1], [3].

Strength of the compression zone is depended on strength of the compressed concrete slab. Resistance of the concrete slab in compression can be predicted from:

$$
F_{c, s c, R d}=b_{e f f} \cdot \lambda \cdot x \cdot \eta \cdot \varsigma \cdot f_{c d}+F_{c, s, R d}
$$

where $f_{c d} \quad$ is the design compressive strength of concrete,

$\lambda, \eta$ are the factors allowing rectangular stress distribution, and depth of the compression zone according to [4],

$x \quad$ is the effective height of the concrete slab,

$\varsigma \quad$ is the coefficient allowed influence of cracks on compressive strength of concrete,

$F_{c, s, R d}$ is the strength of reinforcement steel bars in compression zone, and

$b_{\text {eff }}$ is the effective width of the concrete slab.

Effective width $b_{\text {eff }}$ of the concrete slab according to [1] is depended on the span of adjacent beams and can be calculated as:

$$
b_{e f f}=b_{0}+\sum b_{e i}
$$

where $b_{0} \quad$ is the distance between studs,

$b_{e i} \quad$ is the effective width of concrete slab from every side of the beam, equal to $L_{e} / 8$

In [5], a proposed formula to compute the width of the concrete slab is depended on the height of the column profile.

$$
b_{\text {eff }, \text { conn }}=b_{0}+0,7 \cdot h_{c} \leq b_{\text {eff }}
$$

where $h_{c} \quad$ is the height of column profile,

$b_{\text {eff,conn }}$ is the effective width of concrete slab considered strut and tie behaviour,

$b_{\text {eff }} \quad$ as above.

Equation (3) is applied rather in case of external columns, because in other cases compression force from the plate does not transfer only to the column, but to the plate on other side of the column (Fig. 3). 


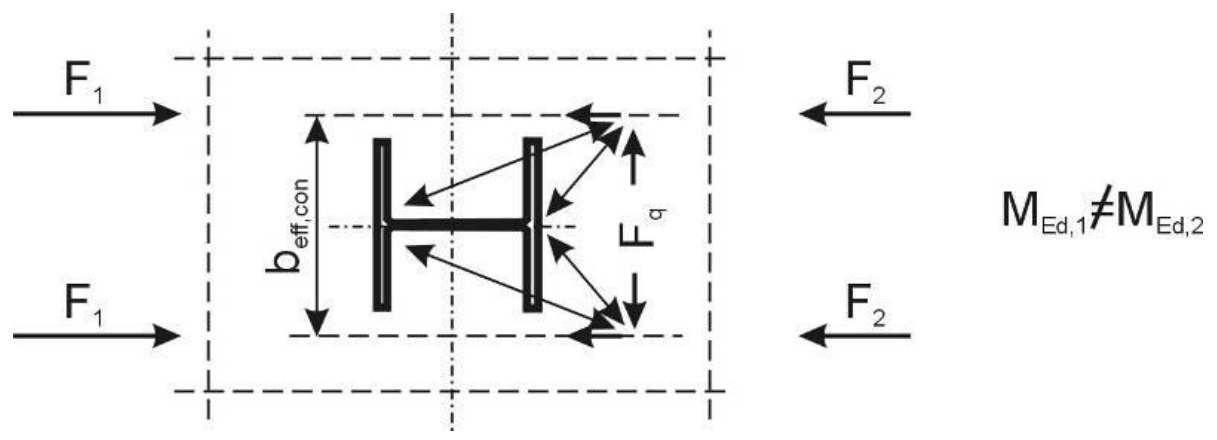

Figure 3: Strut tie model of transfer of the unbalanced force from the reinforced concrete plate to the column

Behaviour of joints in the structures depends not only from his resistance and initial stiffness. On their characteristics influence has also a history of loading. Connections are designed mainly to transfer of loads in service stage. Under loads about not large values, the strongly reinforced concrete slab transfer tension force due hogging moment without the crack (Fig. 4a), tension in the joint is transmitted by the concrete slab and upper bolt row. Usually loading in this stage is large enough that the floor slab crack. After slab cracking tension is passed to reinforcing bars which elongate with local plastification (Fig. 4b). This fact does not have the meaning in case of normal work of the joint in exploitation stage, but affect the stiffness and the resistance in case of sagging moment. Limit state for this stage in shown in Fig. 4b, where forces in the reinforcement and bolts can reach their resistance. Essential for farther joint behaviour is the lever of actual loading on the floors in the moment of column weakening.

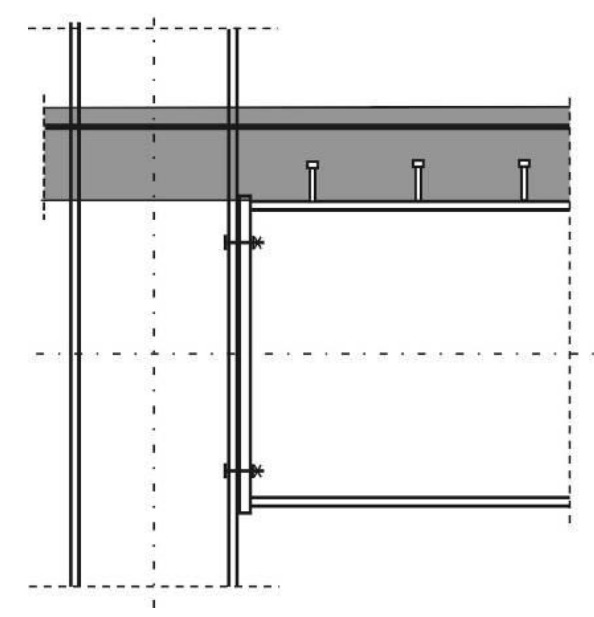

a)

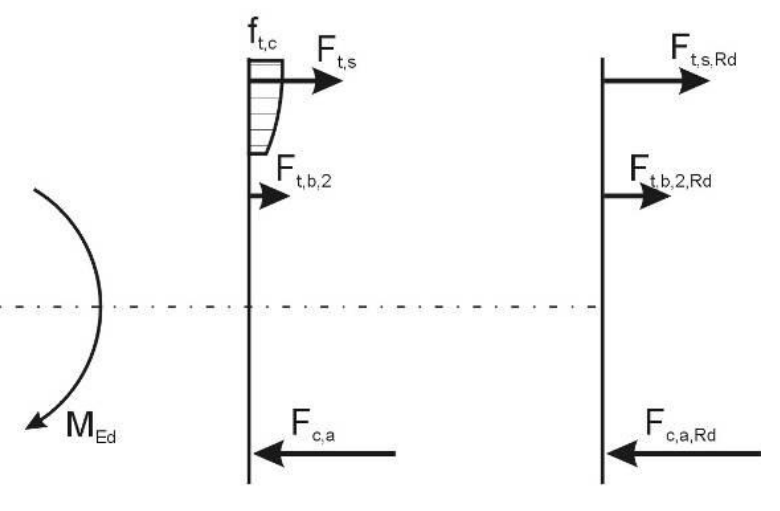

Figure 4: Redistribution of the internal force in joint a) without crack of the concrete slab,

b) after slab cracking.

In concrete elements subjected to cyclic variable loads, degradation of strength of the concrete are observed. Decrease of this strength, after the first cycle of load does not exceed 5 percent. Therefore: 


$$
\varsigma=\left\{\begin{array}{l}
1,0-\text { for uncracked concrete slab (Fig. 2a) } \\
0,95-\text { for cracked concrete slab }(\text { Fig. } 2 b)
\end{array}\right.
$$

Reinforcing steel bars which are placed within the range the compression zone of the concrete slab increase slab resistance and can be considered in calculations. The strength of the reinforcement bars can be predicted from:

$$
F_{c, s, R d}=A_{s} \cdot f_{y, s}
$$

where $A_{s} \quad$ is the area of reinforcing bars on the effective width of the concrete slab,

$f_{y, s} \quad$ is the yield strength of steel bars.

Resistance of the compression zone is limited by their depth. The depth of the compression zone is limited by a height of the concrete slab $\left(x \leq t_{\text {slab }}\right)$.This condition is usually performed, because the bolted connection in the tension zone for exploitation stage is designed constructively.

\section{Initial stiffness of the composite joint}

Calculation of the initial rotational stiffness of the joint requires the knowledge of the stiffness of each component and the position of component in the joint model. The behaviour of each component can be defined as elastic - plastic or rigid-plastic [6]. In connections subjected to the hogging and sagging bending moment, some components of the joint were subjected to opposite direction loading or posses' initial deformability due to earlier state of the loading, what should be taken into account.

The proposed component mechanical model for joint subjected to hogging and sagging bending moment is shown in Fig. 5.

a)

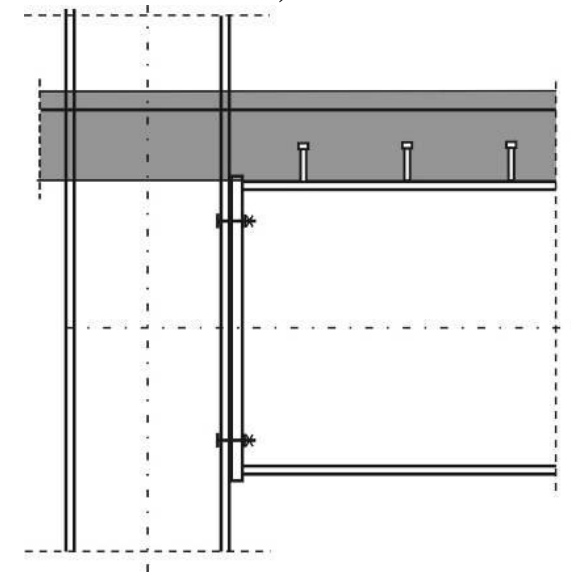

b)
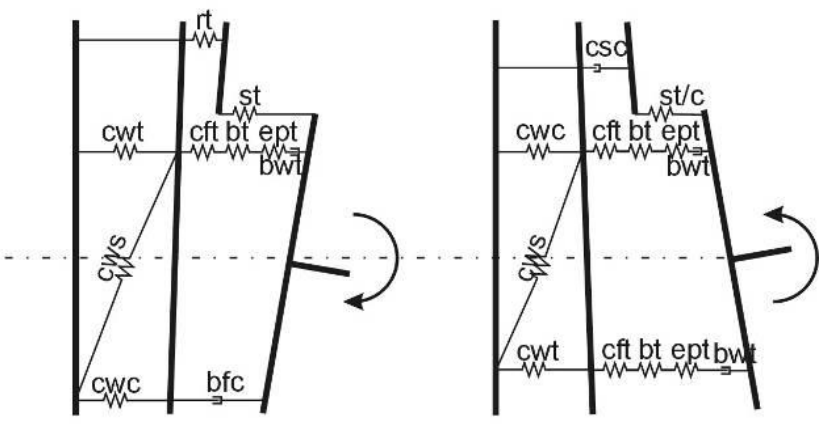

Figure 5: Mechanical model for composite joint subjected to: a) hogging bending moment, b) sagging bending moment.

Initial stiffness of the joint is calculated as follows: 


$$
S_{j}=\frac{E \cdot z^{2}}{\mu \cdot \sum_{i} \frac{1}{k_{i}}}
$$

where $k_{i} \quad$ is the stiffness coefficient for each component of the joint,

In composite joint under sagging moment the following components should be included:

- column web in tension (cwt),

- column web in compression (cwc),

- column web in shear (cws),

- column flange in bending (cft),

- end plate in bending (ept),

- bolts in tension (bt),

- beam web in tension (bwt),

- concrete slab in compression (csc) and

- shear stud under compression (st/c).

Stiffness coefficients of the most of components of the connection are known and can be obtained according to [2].

Concrete slab in compression is usually treated as stiff, and then stiffness coefficient for this element is taken as infinity. However, due to loading of the plate by global prying force, and taking into account slab cracking caused by hogging moment, deformations of the concrete slab must be taken into account in the analytical model. Adopting the formulae given in [6], the coefficient of the stiffness for the concrete slab may be predicted as:

$$
k_{c, s, c}=0,8 \cdot \frac{E_{c}}{E} \cdot \sqrt{b_{e f f} \cdot x}+\frac{w}{s_{r}} \cdot l
$$

where $E_{c} \quad$ is the secant Young modulus for the concrete,

$w \quad$ is the mean crack width under hogging moment,

$s_{r} \quad$ is the maximum crack spacing under hogging moment,

$l$ is the range of hogging moment on the length of the beam,

$b_{e f f}, x, E$ as above.

Slip in the connection between steel beam and concrete slab, under sagging bending moment, can be accepted identical as for joints under hogging bending moment according to [1], taking into account the character of deformations of the connectors. When failure mode of connectors is elastic, the deformations due to loading in service stage should be allowed. The stiffness coefficient of the shear connector is taken from the experimental research, as the relation of the load to the connector slip under loading of the $70 \%$ characteristic shear strength of connector. Test results for shear connectors are presented in [7], [8].

\section{Internal forces in the joint under accidental loading}

Rules for analyses of the structure using tying method were introduced into the UK Building Regulations [9]. In this approach, all members in the floor structural system are required to be 
effectively tied together. This method assumes that the accidental loading at the moment of damage equals to the sum of 0,3 imposed load and 1,05 of the dead load. In the service stage the shear force in the joints, calculated using loading equal to the sum of 1,6 imposed load and 1,4 of the dead load is greater than the shear force due to accidental load, so the beams do not fail by shear and the tying force. In practice, there is requirement that the tensile strength of connections is at least equal to the design shear force.

\subsection{Tying action}

When the intermediate column is removed, adjacent beams and surrounding structural elements should carry current loading trough catenary action. Behaviour of this system is depended on the stiffness and strength of adjacent beams and joints. If joins are stiff enough, the beam become continuous (double span beam). If connections are a simply joints, elements become to tie structure. The scheme of catenary method is shown in Fig. 6.

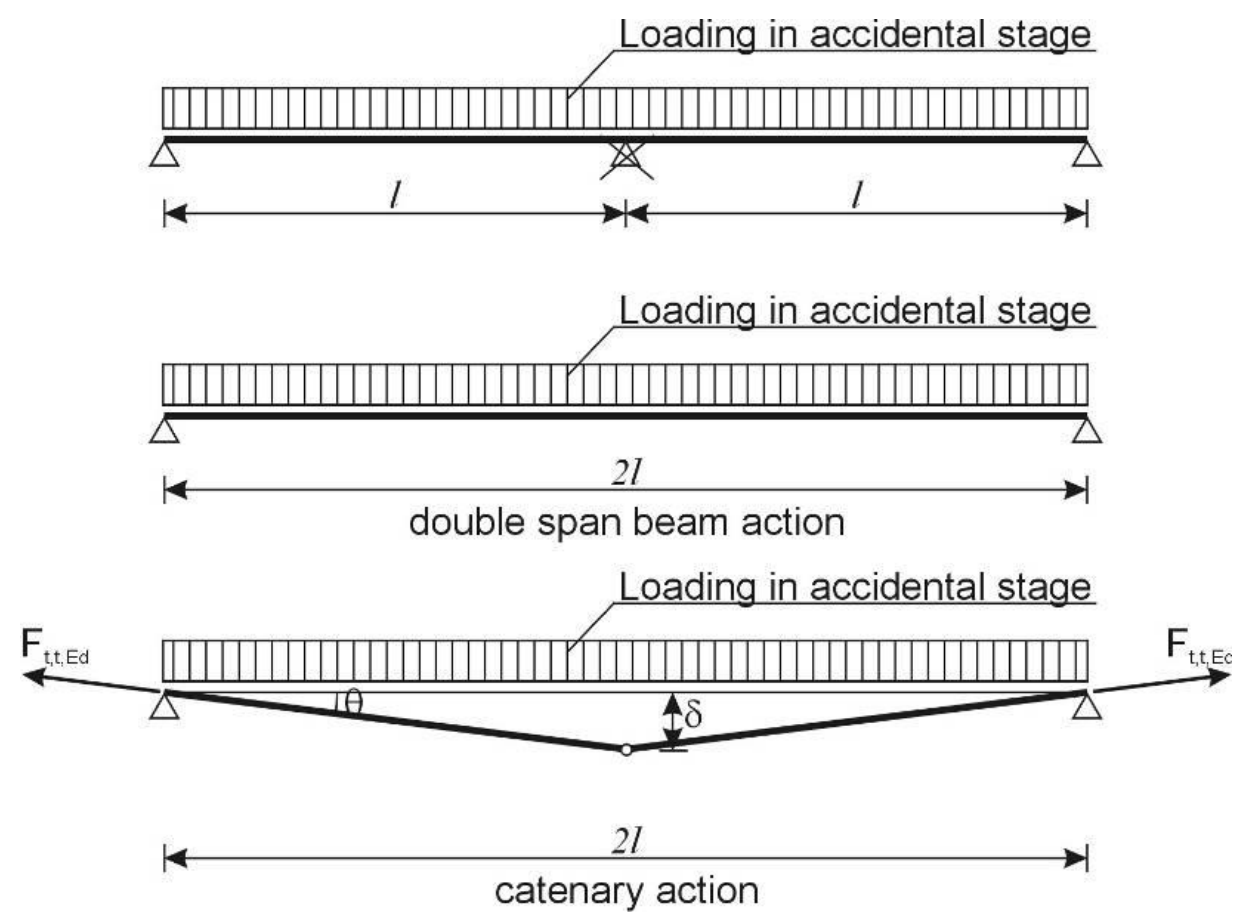

Figure 6: Schema for analysis of catenary action.

Shown in Fig. 6. simple analytical models corresponded to the structures with ideally stiff elements or with ideally pined joints. In real structure joints neither are nor sufficiently stiff, nor ideally pinned. Therefore axial forces and bending moment in joints in the structure are depended on load and stiffness of the structure. Fig. 7 shows relationship between the bending moment in the joint and the translation stiffness of the support (weakening column). This drawings are prepared for beams IPE 300 , beam span equal to $6 \mathrm{~m}$ and to the load in accidental stage $15 \mathrm{kN} / \mathrm{m}$. 


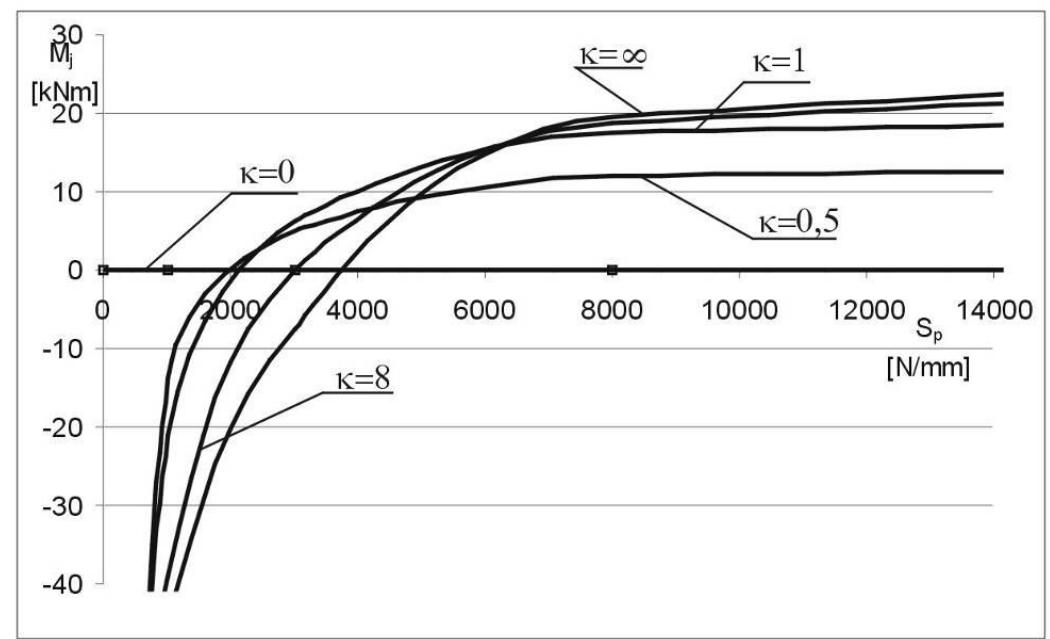

Figure 7: Support stiffness - moment in the joint relationship.

Where $\kappa$ is the joint to beam stiffness ratio.

\subsection{Global prying action}

When the intermediate column is removed by due to impact or blast, joint this column and adjacent beams surrenders to the considerable dislocation. Displacement of the node causes the rotation of the beam. Elongation of the beam due to rotation (Fig. 8) causes compression force (prying force). The value of the prying force is depended on geometry of the structural system and his stiffness. To them the structure is stiffer, this the prying force increased.

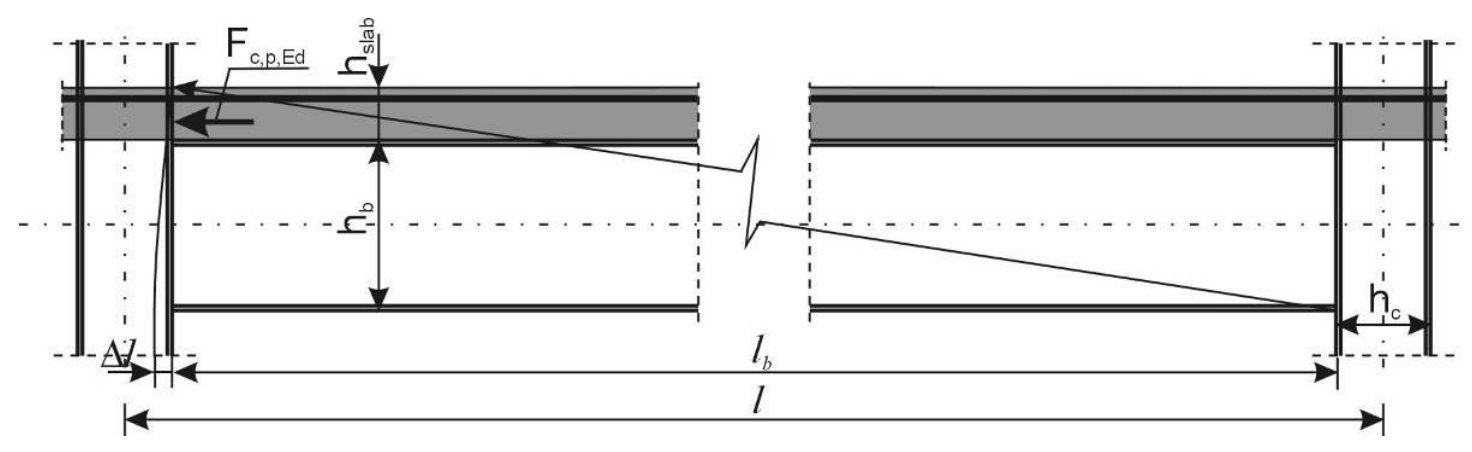

Figure 8: Schema generation of prying force.

The greatest value the prying force attains at the deformation $\delta$ equal total height of the composite beam. In regards to point applications, the prying force loaded mainly the floor slab. Maximum value of this force can be computed from the formula:

$$
F_{c, p, E d}=\frac{1}{2} \cdot\left(1-\frac{l_{b}}{\sqrt{\left(h_{b}+h_{\text {slab }}\right)^{2}+l_{b}^{2}}}\right)\left(E \cdot\left(A_{s}+A_{b}\right)+E_{c} \cdot b_{e f f} \cdot h_{s l a b}\right)
$$


where $A_{b} \quad$ is the cross-section area of the beam,

$h_{b} \quad$ is the height of the beam section,

$h_{\text {slab }}$ is the height of the concrete slab,

$l_{b} \quad$ is the span of the beam in the wide of column,

$b_{e f f}, A_{s}, E$ as above.

\subsection{Influence of the axial forces on characteristics of the joint}

Axial forces due to effects of the global prying action and tying action in structure affect on components of the joint. Values of these forces are depended to the deformation and the stiffness of the structure. They do not act at the same time. In first phase, when vertical deformation is not large, both prying and tying forces are increase whereat prying force increase quickly. In second phase, when vertical displacement exceed height of the beam tying force constantly increasing bat prying force decrease (Fig. 9).

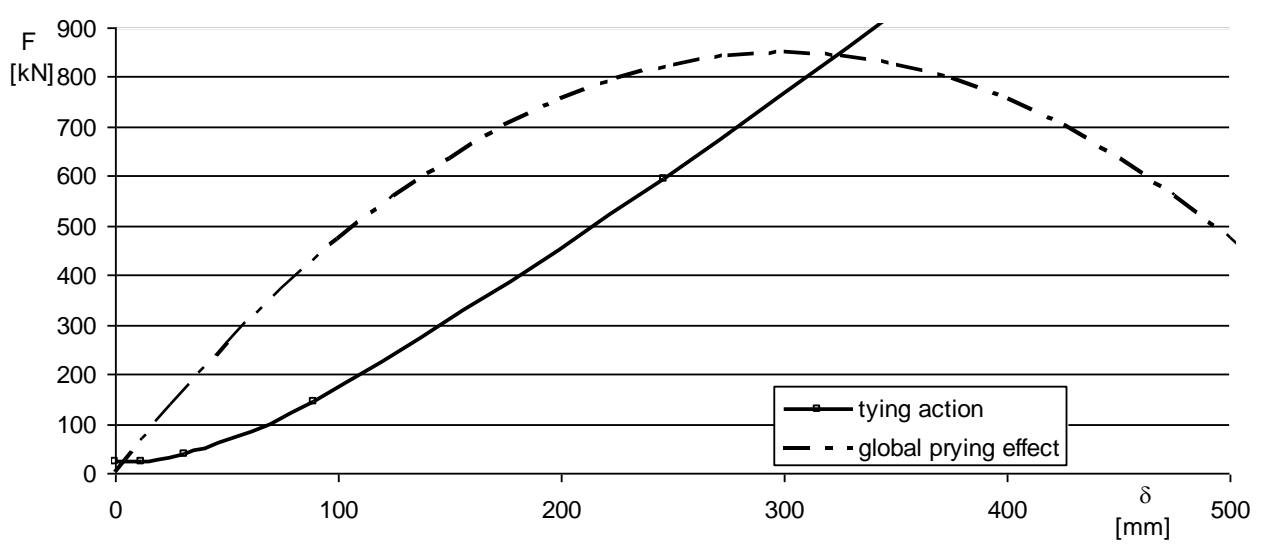

Figure 9: Vertical displacement - axial force relationship for tying and global prying effect.

Proposed mechanical model of the joint with the allowance of the influence of the axial force is presented on Fig. 10

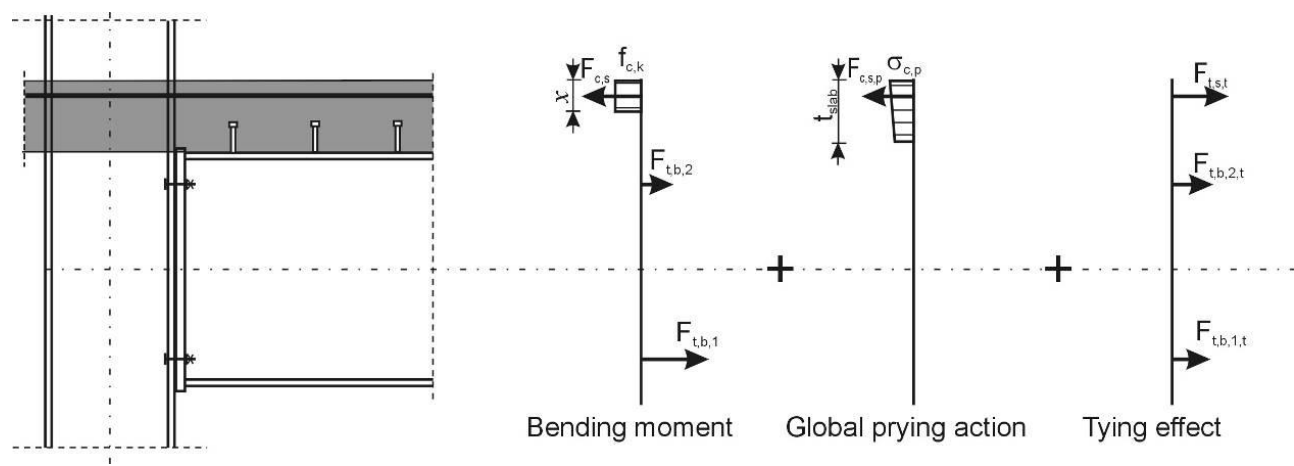

Figure 10: Redistribution of the internal forces in composite joint with allowance of the axial force. 


\section{Conclusion}

In steel-concrete composite structures joints are as a rule designed for condition of hogging bending moments acting in the joints. In accidental situations, for example when internal column is lost, connections must transfer sagging bending moments. Change of moment direction, forces due to the tying effects and global prying force on distribution of internal forces in the connection and its stiffness should be taken into account

An analytical model presented in the paper is based on the component method proposed in Eurocodes. This procedure allows additional component of the connection, such as the concrete floor slab in the compression, and influence of the history of loading.

\section{Acknowledgements}

Paper was prepared in the framework of the project No 457/N-COST/2009/0 of the Ministry of Science and Higher Education, Poland.

Apparatus/Equipment purchased in the project No POPW.01.03.00-18-012/09 from the Structural Funds, The Development of Eastern Poland Operational Programme co-financed by the European Union, the European Regional Development Fund.

\section{References}

[1] PN-EN 1994-1-1 Eurocode 4. Design of Composite Steel and Concrete Structures. Part 1-1: General rules for buildings. PKN 2008.

[2] PN-EN 1993-1-8 Eurocode 3. Design of Steel Structures. Part 1-8: Design of joints. PKN 2005.

[3] BRÓDKA J. KOZŁOWSKI A. Design and calculation of the connections and joint in steel structures. T.2. Warsaw, PWT 2009 (in polish).

[4] PN-EN 1992-1-1 Eurocode 2: Design of concrete structures - Part 1-1: General rules and rules for buildings. PKN 2008.

[5] Demonceau, J.F., Jaspart, J.P., Klinkhammer, R., Oerder, R., Weynand, K., Labory, F., Cajot, L.G. (2008). Recent developments on composite connections" In International Conference EUROSTEEL 2008, 2008 (pp. 447-452). Graz.

[6] Ahmed, B., Nethercot, D.A. (1997). Prediction of initial stiffness and available rotation capacity of major axis flush endplate connections. Journal of Constructional Steel Research. Volume 41(1), pp. 31-60.

[7] Kucharczyk, W. (2001). Steel - concrete composite beams in building structures. Częstochowa: Wydawnictwo Politechniki Częstochowskiej.

[8] Kozłowski, A., Pisarek, Z. (2008). Shear connectors for steel - concrete composite beams. Steel structures. Poland: Polish Chamber of Steel Structures.

[9] Byfield, M.P., Paramasivam, S. (2007). Issues in the migration of progressive collapse through the tying force method for steel framed buildings with simple connections. Steel and Composite Structures - Wang \& Choi (eds). London: Taylor \& Francis Group. 